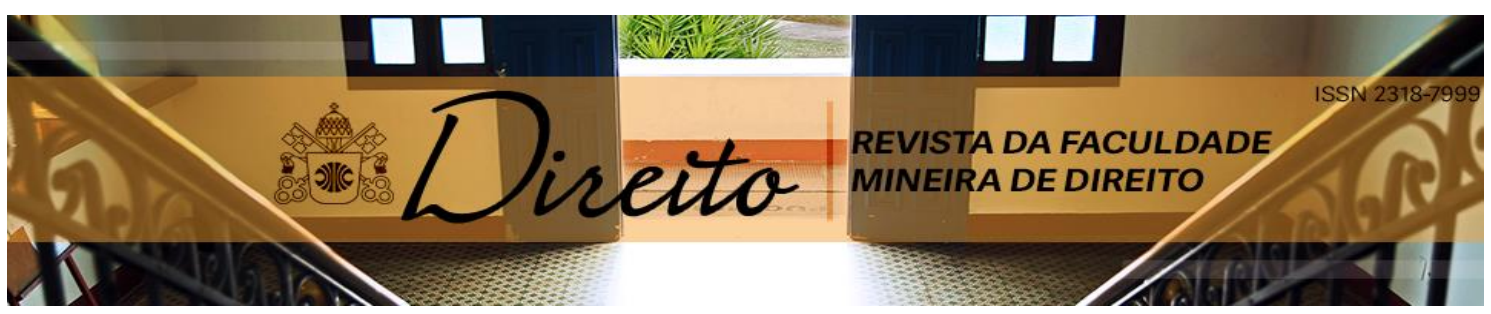

\title{
CONSELHOS DE POLÍTICAS PÚBLICAS: espaços legítimos de participação social na defesa das políticas públicas
}

\author{
PUBLIC POLICY COUNCILS: legitimate spaces for social participation in the defense \\ of public policies
}

\author{
Nilva Lúcia Rech Stedile ${ }^{1}$ \\ Caroline Ferri² \\ Mara de Oliveira ${ }^{3}$
}

\begin{abstract}
Resumo
O presente artigo trata do tema dos Conselhos Municipais, considerados estes como espaços políticos propícios à proteção social e a defesa das políticas públicas e dos direitos a ela vinculados. Esses Conselhos são componentes do processo de descentralização políticoadministrativa, no que se refere a sua organização e gestão, uma vez que se constituem em campos (jurídico legais) de compartilhamento de responsabilidades entre as estruturas governamentais em seus três níveis - nacional, estadual, municipal - e a sociedade civil organizada. Objetiva-se mostrar que a ocupação de unidades públicas legítimas de participação social, como os Conselhos, é uma das possibilidades de resgate do processo de democratização da coisa pública. Com uso de uma metodologia analítica, o artigo analisa a questão dos conselhos de políticas públicas enquanto instrumentos de defesa de direitos, destacando a ideia da participação social como um elemento central no processo de democratização, mostrando que estes Conselhos podem se configurar como espaços propícios de constituição de práticas democráticas.
\end{abstract}

Palavras-chave: Controle social; Conselhos de Políticas Públicas; Democratização da esfera pública; Participação social.

Abstract
This is about of Municipal Councils, considered as political spaces conducive to social protection and the defense of public policies and related rights. These councils are components of the political-administrative decentralization process, as regards their organization and management, since they constitute legal (legal) fields of responsibility sharing between governmental structures at their three levels - national, state, Municipal - and organized civil society. The objective is to show that the occupation of legitimate public units of social participation, like the Councils, is one of the possibilities of redemption of the process of democratization of the public thing. With the use of an analytical methodology, the article analyzes the issue of public policy councils as instruments of defense of rights, highlighting the idea of social participation as a central element in the process of democratization, showing that these Councils can be configured as democratic practices.

Key words: Social control; Public Policy Councils; Democratization of the public sphere; Social participation.

Artigo recebido em 18 de dezembro de 2016 e aprovado em 10 de abril de 2017.

1 Doutora em Enfermagem pela Universidade Federal de São Paulo e professora na Universidade de Caxias do Sul, Caxias do Sul, Rio Grande do Sul, Brasil.

2 Doutora em Serviço Social pela Pontifícia Universidade Católica do Rio Grande do Sul e professora na Universidade de Caxias do Sul, Caxias do Sul, Rio Grande do Sul, Brasil.

${ }^{3}$ Doutora em Direito pela Universidade Federal de Santa Catarina e professora da Universidade do Estado do Rio de Janeiro, Rio de Janeiro, Brasil.

RFMD, Belo Horizonte, v. 20, n. 39, p. 61-90, out./abr. 2017 - INSS 2318-7999 


\section{INTRODUÇÃO}

Particularmente a partir da década de 1990, continuando neste século até o presente, as políticas de ajuste neoliberal (com suas várias formatações) atingem com força a proposta de Proteção Social brasileira veiculada pela Constituição Federal de 1988 e leis infraconstitucionais, desmontando propostas vinculadas à direitos e políticas públicas de caráter universais, substituindo-as por ações, projetos e programas focalizados e emergenciais com conexão ideológica a iniciativas, entre outros, de "neo-solidarismo, à refilantropização, a política de mínimos sociais, [...] a emulsão do empreendedorismo" (MOTA, 2010, p. 51). Isso tem resultado em desresponsabilização estatal (questão nodal a desregulamentação de direitos), o que tem incluído a privatização da previdência social, da saúde e da educação públicas, por exemplo. A contraposição a lógica dominante supõe organização e mobilização social como resistência a essa.

Mesmo com os obstáculos pelos quais passou (e passa) - desde os primeiros momentos da formação dos Conselhos, no início da década de $1990^{1}$ - a participação nos processos decisórios das políticas públicas, acredita-se que um dos espaços políticos propícios e veiculadores de formas de resistência podem ser os Conselhos de Políticas Públicas e os de Defesa de Direitos, enquanto componentes do processo de descentralização político-administrativa do Estado brasileiro, no que se refere a sua organização e gestão. Essa descentralização implica articulação, a partir de competências específicas, mas complementares, das complexas estruturas governamentais em seus três níveis (nacional, estadual e municipal), compartilhando responsabilidades: poder de decisão e de execução e financiamento. Pressupõe, também, um sistema participativo, por meio do qual a sociedade civil organizada toma parte tanto nas decisões políticas como no acompanhamento das ações desenvolvidas, configurando o que vem sendo denominado controle social.

\footnotetext{
${ }^{1}$ Lembrando que no mesmo momento histórico de aprovação da Constituição Federal de 1988 e edificação de leis especificas das políticas sociais e ambientais ocorre (início dos anos 1990) a adesão do Brasil, a exemplo dos demais países da América Latina, ao ajuste neoliberal "enquanto movimento de rearticulação do capital, da lógica do capitalismo e de sua relação de exploração e desigualdade, configurada, dentre outros fatores, na "necessária" subordinação dos países periféricos ao capital internacional." (OLIVEIRA, 2005 , p. 33). Isso significou a redução da intervenção do Estado na vida social ao mínimo.
} 
Importa ressaltar que ao se apontar os Conselhos enquanto espaços de possibilidades não se descartam os estudos e pesquisas que assinalam as dificuldades e obstáculos da participação social junto a gestão pública.

Primeiramente, os empecilhos têm ligação com a cultura política brasileira negadora de direitos o que remete conhecer e analisar a história da opressão, do patrimonialismo, do clientelismo e da apropriação da coisa pública pelo privado, onde não há a efetivação nem o princípio da igualdade formal-jurídica e nem o da igualdade social real (CHAUI, 2001). Isso significa, que "as leis são necessariamente abstratas e aparecem como inócuas, inúteis, ou incompreensíveis, feitas para ser transgredida e não para ser cumpridas nem, muito menos, transformadas" (CHAUÍ, 2001, p. 90), resultando, muitas vezes, no descrédito quanto as finalidades e influência dos Conselhos.

Um segundo aspecto a ser aferido são as insuficientes e, por vezes segregadoras, ferramentas de (de) igualdade política entre os cidadãos, portanto, restritivas. Com certeza há "desigualdades no acesso à informação, na capacidade de influenciar o governo e na capacidade de organização [dos diferentes atores]" (COELHO, 2007, p. 79). Tal aspecto alia-se ao primeiro uma vez que há no Brasil uma "arrogância das elites" (CHAUI, 2001) para com a população em geral, particularmente, junto aqueles segmentos mais vulnerabililizados pela pobreza, pela deficiência ou pela cor de pele.

Como terceiro obstáculo, está a formatação que assume os movimentos sociais no final dos anos 1980 e começo dos anos 1990 com reestruturação e redimencionamento de suas plataformas e a multiplicidade de lutas geradas "pelo capitalismo global moderno. [...] a passagem da antiga luta de classes para todas essas lutas pós-modernas, ecológicas, culturais, sexuais etc. foi aberta pelo capitalismo global. A base dessas lutas é a globalização capitalista." (ZIZEK; DALY, 2006, p. 185 apud DURÁN; GERSCHMAN, 2014, p. 887).

Por fim, sem que isso contemple todas as outras barreiras, estão os entraves, como afirma Evelina Dagnino, de perversidade e de dilemas

[...] instaurando uma tensão que atravessa hoje a dinâmica do avanço democrático no Brasil. Por um lado, a constituição dos espaços públicos representa o saldo 
positivo das décadas de luta pela democratização, expresso especialmente - mas não só - pela Constituição de 1988, que foi fundamental na implementação destes espaços de participação da sociedade civil na gestão da sociedade. Por outro lado, o processo de encolhimento do Estado e da progressiva transferência de suas responsabilidades sociais para a sociedade civil, que tem caracterizado os últimos anos, estaria conferindo uma dimensão perversa a essas jovens experiências, acentuada pela nebulosidade que cerca as diferentes intenções que orientam a participação. Essa perversidade é claramente exposta nas avaliações dos movimentos sociais, de representantes da sociedade civil nos Conselhos gestores, de membros das organizações não governamentais (ONGs) envolvidas em parcerias com o Estado e de outras pessoas que de uma maneira ou de outra vivenciam a experiência desses espaços ou se empenharam na sua criação, apostando no potencial democratizante que eles trariam. (DAGNINO, 2004, p. 198).

Tais obstáculos tem significado, entre outros, tencionamento no sentido de tornar os Conselhos extensões das tradicionais formas de apropriação da coisa pública pelo privado. Nesse sentido, a gestão participativa "tem uma forte carga retórica e, muitas vezes, é vivida mais como um 'desejo' que como proposta efetiva a ser, de fato, implementada". (NOGUEIRA, 2005, p. 151-152).

Entretanto, um número significativo de estudos, incluindo das autoras desse artigo, indicam que há experiências positivas que tem incluído segmentos sociais em geral e de usuários que até então encontravam-se distantes das discussões sobre direitos, a proposição e a implementação de políticas públicas. "Lavalle, Houtzager e Achrya encontraram evidências de que os novos espaços de participação e deliberação podem favorecer a representação de grupos 
sociais até então excluídos" (COELHO, 2007, p. 80). É nessa perspectiva que se encaminha o presente artigo.

Para isso, tem-se por finalidade contribuir, com algumas premissas teórico-conceituais, para uma melhor compreensão sobre essa modalidade de Conselhos. Aponta-se, de forma problematizadora e analítica, o papel desses conselhos e a importância da participação social - quesito essencial ao processo de democratização do Estado brasileiro e do controle social e à construção da esfera pública desejada.

\section{CONSELHOS DE POLITICAS PÚBLICAS E DEFESA DE DIREITOS: A PREMISSA DO CONTROLE SOCIAL}

A partir da metade da década de 1990, muitos foram os Conselhos criados, tendo em vista a reforma do Estado brasileiro e, junto a essa, a descentralização político-administrativa das políticas públicas, instituídas por leis regulamentadoras.

Os Conselhos de Políticas Públicas e os de Defesa de Direitos, fóruns de reconhecimento legal, são aqui compreendidos como unidades políticas, espaços contraditórios de construção de uma esfera pública, assentada em princípios da democracia participativa. Formas de sociabilidade regidas pelo reconhecimento do outro como sujeito de interesses válidos, valores pertinentes e demandas legítimas (STEIN, 1997). Dito de outra forma, os Conselhos aqui referidos, em acordo a Tatagiba (2002) caracterizam-se por:

[...] serem espaços públicos, com composição plural e paritária [...]; terem no processo dialógico o instrumento privilegiado de resolução dos conflitos inerentes as diversidades dos interesses em jogo [...] funcionarem como instancias deliberativas, com competência legal para formular políticas e fiscalizar sua implementação apontando no sentido da democratização da gestão [pública]. (p. 54-55). 
Têm caráter permanente, natureza deliberativa pública, efetivadas através de discussões acerca das diretrizes e ações necessárias à efetivação dos aspectos da proteção social vinculados àqueles grupos e as políticas públicas, assim como o controle social, fiscalizando e avaliando os resultados das ações. Com isso, têm, como uma de suas competências políticas, a luta pela garantia de direitos legalmente constituídos.

Controle social, definido de acordo com a Constituição Federal de 1998 como "instrumento de efetivação da participação popular no processo de gestão político-administrativa financeira e técnico-operativa, com caráter democrático e descentralizado" (PNAS, 2004, p. 45). Ele expressa o poder que a sociedade civil tem para intervir nas políticas públicas.

O controle social assim entendido somente pode ser efetivado mediante a participação da população e a instituição de mecanismos que possibilitem ao cidadão integrar-se ao processo de definições políticas

Os conselhos são exemplos claros de um dos mecanismos legalmente constituídos para efetivação do controle social. Para que seja resolutivo é necessário: superar a cultura historicamente constituída de que o Estado é detentor do conhecimento para a tomada de decisões que afetam o coletivo; promover a descentralização das decisões; selecionar adequadamente as representações legitimamente constituídas; facilitar formas de organização da população para o pleno exercício da democracia.

Portanto, o controle social "[...] inscrito na Constituição é o da participação da população na elaboração, implementação e fiscalização das políticas [públicas]" (BRAVO, 2001, p. 45), significando controle ao poder do Estado, ${ }^{2}$ pela organização da sociedade civil, que, no caso dos Conselhos, autoriza aos mesmos: avaliar e avalizar, a partir de critérios de qualidade estabelecidos, programas, projetos, serviços; reivindicar, denunciar, pressionar, fiscalizar; exigir qualidade dos serviços, como direito, destituindo o favor. Controle que permite, através do envolvimento de diferentes sujeitos,

\footnotetext{
${ }^{2}$ Esse controle se perfaz, agregadamente, também, à prestação de serviços das diversas e diferentes entidades governamentais ou não governamentais.
} 
[...] acesso aos processos que informam as decisões no âmbito da sociedade política. Permite participação da sociedade civil organizada na formulação e na revisão das regras que conduzem as negociações e a arbitragem sobre os interesses em jogo, além do acompanhamento da implementação daquelas decisões, segundo critérios pactuados (RAICHELIS, 1998, p. 41).

Entretanto, a fiscalização dos direitos de cidadania, pela sociedade, junto aos Conselhos não pode ser realizada de forma isolada. Cabe a esses foruns, através de seus representantes, envolverem os vários sujeitos que compartilham da posição aqui assumida, assim como, acionarem outros mecanismos também entendidos como de controle social: Ministério Público, órgão de defesa do consumidor, meios de comunicação oficiais, conselhos profissionais (BRAVO, 2001).

Ou seja, o controle social somente é exercido se for como prerrogativa que se dá no e para o coletivo, assim, não individuais nem particulares mas necessárias à "assunção de responsabilidade pública pela sociedade" (BATTINI, 1998, p. 34).

Salienta-se que o controle social é elemento vinculado ao direito político de cidadania. Logo, deve ser compreendido na perspectiva do direito de diferentes sujeitos sociais participarem do espaço de construção da esfera pública. Não se pode veicular controle social, sem participação social o que requer um processo democrático, onde a pluralidade é condição fundamental.

A definição e ação dos Conselhos de Políticas Públicas e de Defesa de Direitos somente é possível com os processos de democratização do Estado brasileiro, logo, da esfera pública, pós Constituição Federal de 1988. Nesse sentido, tal democratização torna-se princípio fundamental ao processo de criação/ocupação dos Conselhos, como unidades políticas.

\section{DEMOCRATIZAÇÃO DA ESFERA PÚBLICA: PRINCÍPIO FUNDAMENTAL AO PROCESSO DE CRIAÇÃO/OCUPAÇÃO DAS UNIDADES POLÍTICAS}


Muitos são os discursos em favor da democratização, mas é preciso esclarecer objetivamente que procedimento democrático está sendo referido.

A democratização é valor universal, que se aprofunda, que conjuga indissoluvelmente reformas políticas, econômicas e sociais. Trata-se, consequentemente de "um processo e não de um estado" (COUTINHO, 2000, p. 23). Ela é categoria necessária na criação/ocupação de unidades que possam ter força política - no caso dos Conselhos, legal e orgânica - de veicular contraposição aos interesses das elites dominantes.

Enquanto processo, a democratização pressupõe a defesa e a construção de alternativas capazes de reformar o Estado, ${ }^{3}$ não na perspectiva dominante atual de concentração de poder, mas na perspectiva de retirar o poder de decisão das mãos "daqueles e sistemas de delegação política que alienam a capacidade de controle e de influência dos eleitores sobre seus representantes." (SADER apud SANTOS, 2002, p. 658). Assim, é processo que aponta à socialização da política e do poder, o que significa "reformular a relação dos governos com a cidadania, de colocar as estruturas e o governo sob o controle direto da população, de levar a cabo uma tentativa de mobilização permanente dos cidadãos, apontando para outra forma de Estado [...]" (SADER apud SANTOS, 2002, p. 659).

Isso se dá no exercício da luta, na disputa política, através da correlação de forças entre lógica dominante e lógica de contraposição. A democracia, com esse fundamento, "é concebida como a construção coletiva do espaço público, como plena participação consciente de todos na gestão e no controle da esfera política" (ROUSSEAU apud COUTINHO, 2000, p. 50).

Portanto, o processo democrático, aqui defendido, não está arquitetado em regras formalizadas de simples recondução ou de nova condução de governantes a cargos executivos e a um parlamento, mas está consubstanciado na defesa inflexível da participação da sociedade organizada, na decisão, gestão e no usufruto acerca dos destinos da sociedade. Para isso, é preciso incorporar o maior número de cidadãos ao processo social, que sejam capazes de

\footnotetext{
${ }^{3}$ Estado “[...]que independentemente de seu tamanho, seja, acima de tudo, permeável às necessidades sociais" (PEREIRA, 2001, p. 41).
} 
organização e, nessa, expressarem suas necessidades, obtendo conquistas que somente serão efetivadas pela mobilização desses sujeitos.

No entanto, o protagonismo dos sujeitos, em um grande número de situações, não é consciente, nem defensor das premissas acima levantadas, muito pelo contrário, é significativo o número de casos em que o usuário dos serviços, representantantes daquele grupo social, associação, entidade, seja um dos sujeitos que chame a si a defesa da ideologia dominante, enquanto procedimento de alienação. Mas se acredita que os espaços políticos e os Conselhos o são, podem contribuir para a constituição dos sujeitos democráticos, defensores da emancipação humana.

A democratização, assim como a participação aqui caracterizadas, não estão dadas a priori: faze parte de um processo em construção, devendo ser instigada, exercitada, uma vez que "[...] não se adquire o hábito com facilidade" (DEMO, 1988, p.72).

Ainda sobre democratização, é importante destacar que seu processo se instala, tantos nos espaços internos - unidades políticas - quanto nos espaços externos - sociedade. Por isso, esse processo exige também algumas ações operacionais que vão desde a socialização de informações nos espaços internos, que permita aos diferentes sujeitos exercer seu poder de deliberação com a maior clareza possível, até o repasse à sociedade das discussões e deliberações tomadas nas unidades políticas. Isso exige transparência, informações fidedignas, formação e, participação política.

\section{PARTICIPAÇÃO POLITICA: ELEMENTO BÁSICO DO PROCESSO DE DEMOCRATIZAÇÃO, POLITIZAÇÃO E CONTROLE SOCIAL}

Os Conselhos são organismos nos quais deve haver a participação de distintos sujeitos políticos coletivos, ${ }^{4}$ através de representação da sociedade (de interesses) - política e civil ${ }^{5}$ - o que exige a existência da pluralidade. Portanto,

\footnotetext{
4 Sujeitos políticos coletivos, uma vez que os Conselhos não são formados por representação de indivíduos, mas por representações de coletividades: associações, entidades, setores, grupos sociais, etc., em que indivíduos as representam.

5 A perspectiva de sociedade política e sociedade civil aqui adotada baseia-se na lógica gramsciana. Para melhor entendimento ver GRAMSCI, Antonio em seus textos: Cartas do cárcere. 3.ed., Rio de Janeiro: Civilização Brasileira, 1987; Os intelectuais e a organização da cultura. 5. ed., Rio de Janeiro:
} 
é espaço privilegiado de reconhecimento do direito de todos à participação na vida pública.

Ao haver participação de interlocutores com diferentes posições, esse espaço possibilita a criação de novas relações entre as instâncias da sociedade política e da sociedade civil, e, internamente, nas próprias instâncias (diferentes níveis de governo, órgãos governamentais de mesmo nível e entre as várias entidades, grupos sociais representantes da sociedade civil e usuários). Então, locus por excelência de aprendizagem e exercício de democracia, uma vez que supõe processo de redistribuição de poder decisório entre distintos sujeitos. Isso habilita a criação de disputas e negociações eminentemente públicas, por meio de discussões coletivas, propícias à reflexão e ao debate, sendo assim, repletas também de possibilidades de superação da consciência mitificada. ${ }^{6}$

A participação ${ }^{7}$ é, então, compreendida como o meio pelo qual se constituem os sujeitos sociais coletivos, logo, "[...] processo de criação do homem ao pensar e agir sobre os desafios sociais, nos quais ele próprio está situado" (CAMPOS, 1997, p. 149), ou ainda

[...] um processo de vivência que imprime sentido ou significado a um grupo ou movimento social, tornando-o protagonista de sua história, desenvolvendo uma

Civilização Brasileira, 1985. Ver também, COUTINHO, Carlos Nelson. Gramsci: um estudo sobre seu pensamento político. 2.ed., Rio de Janeiro: Campus, 1992 e BOBBIO, Norberto. O conceito de sociedade civil. Rio de Janeiro: Graal, 1994.

6 A consciência mitificada, no recorte aqui tratado, vincula-se à prática reiterativa, reprodutora da lógica dominante vinculada à ordem do capital, que traduz ações vinculadas ao que Vasquez intitula práxis espontânea. A passagem da consciência ingênua para uma consciência reflexiva exige vários movimentos e ações. Parte-se do pressuposto de que os Conselhos, por serem espaços de repartição de poder, de exercício participativo que veicula a democratização das relações sociais entre os sujeitos, é unidade de poder que pode contribuir na alteração da práxis espontânea para uma práxis reflexiva, uma vez que, concordando-se com Vasquez, “[...] a superioridade do proletariado sobre outras classes ou grupos sociais oprimidas reside precisamente na possibilidade de elevar-se a um nível de consciência consciência de classe - que lhe permite captar-se a si mesmo em sua missão histórico-social e, com isso, orientar, no limite de determinadas condições objetivas, sua própria ação; isso é, passar de uma práxis cega, espontânea, a uma práxis revolucionária reflexiva, ou transformação consciente da sociedade." (VASQUEZ, 1990, p. 294)..

${ }^{7}$ Com certeza, o "tema participação tem forte conteúdo ideológico e comporta diferentes conceitos e definições. Por mais que existam inúmeras tipologias dedicadas a especificar as diferentes categorias de participação - institucionalizada ou 'movimentista', direta ou indireta, focada na decisão ou na expressão, efetiva ou simbólica, todas refletindo ações dedicadas a 'fazer parte' de determinados processos (decisórios ou não) -, estamos aqui diante de um exercício que se repõe constantemente”. (NOGUEIRA, 2005, p. 129). 
consciência crítica desalienadora, agregando força sociopolítica a esse grupo ou ação coletiva, e gerando novos valores e uma cultura política nova. (GOHN, 2005, p. 30).

É através dela - pelos diferentes sujeitos sociais que é oficializada, de fato, a representação em que se pode legitimar a esfera pública.

No caso dos Conselhos de Políticas Públicas e dos de Defesa de Direitos, a participação é que operacionaliza a gestão democrática, na defesa da esfera pública pois

[...] através dela aprendemos a eleger, a deseleger, a estabelecer rodízio de poder, a exigir prestação de contas a desburocratizar, a forçar os mandantes a servirem à comunidade, e assim por diante. Sobretudo, aprendemos que é tarefa de extrema criatividade formar autênticos representantes da comunidade e mantê-los como tais (DEMO,1988, p. 71).

É ela que propicia, de fato, a deliberação, a repartição de responsabilidades, a fiscalização compartilhada. Com ela se efetiva a negociação, através da representatividade dos atores políticos inseridos naquele processo. Ela é, portanto, quem ocupa o espaço de fato. Representa, por isso, "a possibilidade de construção de uma cultura política capaz de conferir visibilidade aos grupos sociais tradicionalmente excluídos do exercício decisório e do usufruto satisfatório dos bens socialmente produzidos" (CAMPOS,1997, p.150). É possibilidade, ainda, de distribuição, diferenciada do tradicional, dos recursos públicos, ou seja, "participar significa influir diretamente nas decisões e controlar as mesmas" (UAMPA apud SANTOS, 2002, p. 58).

A participação permite também, através das diferentes discussões acontecidas junto à unidade política (a exemplo de tantas outras unidades), a movimentação de diferentes saberes, prática fundamental aos processos de 
aprendizagem e ao pleno e consciente exercício da representação dos interesses coletivos.

Nessa lógica, "[...] a participação objetiva o fortalecimento da sociedade civil, não para que esta participe da vida do Estado, mas para fortalece-la e evitar as ingerências do Estado - seu controle, tirania e interferência na vida dos indivíduos".(GOHN, 2011, p. 18).

A participação dos sujeitos políticos coletivos, no controle da vida social, exercido de forma clara e transparente, contribuem, por meio da construção de alternativas, ao rechaço à perspectiva ideológica e política dominante. Contribuem também com a "superação da alienação na esfera política" (COUTINHO, 2000, p. 50).

A participação, no sentido aqui aludido demanda entende-la a partir de determinados aspectos, entre os quais salienta-se: a representação de interesses coletivos; as relações de poder; o pluralismo dos sujeitos coletivos.

\subsection{REPRESENTAÇÃO DE INTERESSES COLETIVOS, BASE DE SUSTENTAÇÃO DAS UNIDADES POLÍTICAS}

A representação de interesses coletivos é o que dá significação, demarca, de fato e de direito, a constituição dos sujeitos políticos coletivos, na unidade política, ou seja, determina os indivíduos que terão o poder de decisão, em igual proporção, por um período determinado. Sujeitos que naquele espaço político, diante das demandas postas, "exercem papel de mediadores" (RAICHELIS, 1998, p. 41). Quer dizer que

[...]ser representante, no sentido de ter representatividade reconhecida para tanto, significa transmitir de maneira mais adequada e similar possível, as idéias e os desejos dos demais membros de uma mesma classe, grupo ou espécie, em prol de um projeto comum de sociedade (COLIN, 1998, p. 155). 
A representação dos sujeitos coletivos absorve alguns quesitos, um deles, que se acredita de fundamental importância, refere-se à representatividade, o que significa que o representante está imbuído de poder de decisão, dado pela coletividade ali representada. A representatividade será tanto mais qualificada quanto o forem as organizações daquela coletividade que o sujeito político representa, isto é, pautada por reflexões coletivas, grau considerável de reivindicação e inserção política nos movimentos societários, em reuniões periódicas de avaliação e prestação de contas daquela delegação, na democracia interna etc. Isso dará maior sustentação às decisões e à gestão dos representantes, bem como maior fiscalização e usufruto por parte da maioria da sociedade.

O representante não é o dono do poder, mas está ali por delegação de um coletivo, representando o poder dado por aquele coletivo, está, desse modo, a serviço de. Portanto, a representação de interesses coletivos determina que haja participação qualificada do sujeito representante na unidade política, que deve saber o porquê da representação e sua importância. Não pode ser, então, apenas um corpo presente nas ações concernentes à prática conselhista, mas sujeito pensante que, por estar investido do poder de decidir e de gestar, deve saber que o usufruto dos direitos a serem efetivados às classes subalternas e a construção de equipamentos sociais e políticos que garantam necessidades humanas básicas ${ }^{8}$ exigem que ele seja sujeito partícipe desse processo e não objeto de cooptação e manipulação. Com certeza, esse é um dos grandes desafios colocados ao processo de construção da contra-hegemonia: utilização consciente do poder.

Outro aspecto que deve-se vincular à discussão sobre representação dos sujeitos coletivos é acerca do que se está denominando de responsabilidade compartilhada entre todos os conselheiros - representantes da sociedade política e da sociedade civil. A mesma deve traduzir o poder de suas atribuições (aqui cerne da questão): deliberativa, fiscalizadora, etc., por meio de parceria e partilha de responsabilidades entre as diferentes representações. Isso deve se

\footnotetext{
${ }^{8}$ Por necessidades humanas básicas entende-se saúde física e autonomia - aquelas cuja não-satisfação adequada implica "sérios prejuízos à vida material dos homens e à atuação desses como sujeitos (informados e críticos)” (PEREIRA, 2000, p. 67).
} 
dar por meio da discussão permanente, que deve negar o pressuposto da amizade, do particularismo, do corporativismo e, vinculados a esses, as noções de harmonia e consenso absolutos nas discussões e decisões. Os conflitos entre as diferentes representações são inerentes e traduzem as distintas posições político-ideológicas e de interesses (COLIN,1998), e devem ser percebidos como tais. Sendo os Conselhos espaços de fazer político,

[...] não podem ser confundidos com confraria de amigos, com um palco de conciliações como o desejam muitos governantes. Por outro lado, também não deve ser entendido como fórum da discórdia e da oposição sistemática, como desejam alguns esquerdistas (CAMPOS, 1997, p. 154).

A responsabilidade compartilhada envolve reflexão sobre as relações de poder, uma vez que cada representante compartilha com os outros o poder de decidir e de gestar sobre algumas competências específicas. Essa responsabilidade deve ser consciente e demarcadora da legitimidade da representatividade. Infelizmente, as relações estabelecidas, em grande parte dos espaços políticos, ocupados pela população, ainda são manifestadas de forma desigual, hierarquizada, o que determina, ainda com muita força, a subalternidade, a permissão, a tutela e as ações egocentradas (particularistas), em que não se efetiva de fato e de direito o compartilhamento consciente das responsabilidades.

O compartilhamento responsável, para ser constituído de fato, necessita de alguns requisitos, de alguma forma veiculados, também, em outros aspectos mas que vale a pena serem ressaltados: informações qualificadas que permitam aos sujeitos saberem e aprenderem sobre a importância e o caráter daquilo que representam - "a desinformação inibe a manifestação e desqualifica o processo de participação"(PRATES, 2003); consciência (que pode ser adquirida nas práticas políticas) que permita compreender a complexidade da dinâmica social; assunção da co-responsabilidade inerente à prática política de decisão e gestão. Responsabilidade que torna a população parceira na definição do destino da 
vida social. Parceria que deve ser feita com todos aqueles que querem remar contra a corrente. Dito de outro modo, responsabilidade compartilhada, a exemplo de outros quesitos é processo que necessita ser construído.

A representação dos sujeitos coletivos pressupõe, então, mobilização social dos coletivos que são representados, e isso exige disponibilidade política - interesse - à participação. Torna-se assim espaço privilegiado de aprendizagem.

Portanto, os Conselhos constituem-se como "[...] espaços de interação que se caracterizam por um tipo de distribuição do poder justificada pela realização de uma tarefa comum, de interesse comum, para o cumprimento de uma responsabilidade comum" (COSTA, 2001, p. 87).

Autorizam, por isso, que os sujeitos ali representantes, ao exercitarem as funções a eles atribuídas, assumam frações de poder, exercidas historicamente apenas pela sociedade política, o que propicia a um grupo maior de sujeitos sociais penetrar, por exemplo, na lógica burocrática estatal, ter acesso a informações e oportunidades (legais, financeiras, etc) e, diante disso, exercer o controle social sobre o Estado junto as políticas públicas. Isso significa uma possibilidade que representações das classes subalternas têm de se constituir, através da práxis, em sujeitos políticos, no entendimento de que é na práxis que se transformam "[...] simultaneamente, o exterior e o interior, as circunstâncias e a consciência"(PALMA, 1986, p. 92).

No entanto, a representação (dada aos conselheiros) para constituir-se em elemento de exercício democrático abrangente e disseminador de consciência política, espaço real de exercício de poder da classe subalterna, ${ }^{9}$ necessita ser socializada a quem de direito - a população representada -, dando visibilidade às ações de representação, assim como às ações das diferentes entidades e organizações prestadoras de serviço, que ali interagem além do próprio Estado.

\footnotetext{
9 “'...] que, em seus movimentos e organizações, têm aglutinado historicamente: operários; assalariados dos setores caracterizados como primário, secundário e terciário, ou seja, trabalhadores dos setores produtivo e improdutivo; os subempregados e desenpregados eventuais; os trabalhadores em potencial, não incorporados ao mercado de trabalho; enfim, todos os segmentos do mundo do trabalho (urbano e rural) que, não possuindo os meios de produção, estão sob o domínio econômico, político ideológico das classes que representam o capital" (CARDOSO, 1995, p. 14).
} 
Quando o sujeito partícipe das práticas conselhistas trouxer para o debate subsídios do coletivo que representa, e levar o retorno das reflexões acontecidas à sua base, contribuíndo com o processo de amadurecimento e politização. Esse movimento pode, gradualmente, auxiliar segmentos grupos e entidades a superarem as visões corporativas por valores maiores (classe em si, classe para si) (PRATES, 2003).

Não há dúvidas de que esse processo pode contribuir com a democratização e politização da sociedade brasileira, mas, para que isso ocorra, é necessário que os representantes tenham "[...] consciência interiorizada de direitos pessoais e coletivos, o reconhecimento da pluralidade de interesses e das idéias, particularmente dos conflitos [existentes na sociedade]" (STEIN, 1997, p .83).

Como qualquer espaço político, os Conselhos encontram-se encharcados de relações de poder, que na seara da defesa dos direitos de cidadania são permeados de conflitos pela divergência de posições e de interesses.

\subsection{RELAÇÕES DE PODER: ENFRENTANDO CONFLITOS,} ESTABELECENDO CONSENSOS

Os Conselhos são espaços que se constituem pelo estabelecimento de compromissos entre diferentes grupos de poder - governamental e não governamental, prestadores de serviços, usuários - que legitimamente representam um determinado grupo social, posição política, etc. Isso não é configurado por cotas de participação que podem ser explicadas, justificadas de forma simples. Aqui cabe, então, tecer algumas considerações sobre o exercício de poder.

No movimento relacional de exercício de poder ${ }^{10}$ múltiplas formas de dominação podem ser exercidas, tanto pela sociedade política, quanto por

\footnotetext{
${ }^{10}$ Para melhor entendimento ver FOUCAULT, Michel. Microfísica do poder. Tradução de Roberto Machado. Rio de Janeiro: Graal, 1986, prioritariamente em sua análise sobre os micro poderes, onde o
} 
representantes da sociedade civil. Como já foi contextetualizado anteriormente, a estrutura autoritária, os traços patrimonialistas de apropriação da coisa pública, por interesses privados, não é privilégio do espaço estatal, dos governantes, mas constituem práticas políticas de diferentes atores, com diferentes ideologias e em diferentes movimentos/instituições, uma vez que são constituintes e constituidores da cultura política brasileira.

Sabe-se que as relações estabelecidas entre os diferentes sujeitos políticos coletivos em espaços de disputa de poder não são relações horizontais. Os interesses e objetivos sobre e na ocupação daquele espaço são permeados pela complexidade de interações entre os diferentes sujeitos.

É comum haver uma heterogeneidade de potencial de conhecimento, de projeto político e legitimidade representativa. Questões que envolvem, muitas vezes, perspectivas contraditórias, que precisam ser reconhecidas, para poderem ser tratadas - e o devem ser. A heterogeneidade de saberes, objetivos e legitimidade podem, e é comum que o façam, na lógica de sociedade hoje constituída, reproduzir a lógica dominante de reforço às relações diferenciadas, em níveis de poder.

Não se está com isso negando saberes e experiências diferenciadas e a importância das mesmas no exercício reflexivo e de aprendizado nos trabalhos coletivos. O que se está chamando a atenção é para o fato de que as relações de poder estabelecidas nesse espaço político (Conselhos) devem ser relações igualitárias. Isso não significa que o sejam, mas os preceitos aqui defendidos definem essa construção - poder igualitário. Com certeza, isso é extremamente complexo, porque a relação entre distintos e divergentes sujeitos políticos o é.

Apesar de legalmente e, na lógica aqui defendida, todos os representantes terem, por direito, igualdade de poder, essa é uma das condições ainda não efetivadas a contento em um grande número de espaços políticos que contam com a representação, de direito, da população, como mostram alguns estudos. Por isso, é um dos grandes desafios a serem enfrentados. Entende-se que a participação dos vários sujeitos políticos nesses fóruns, através de um

autor considera que os mesmos operam múltiplas relações. Ou seja, o poder se exerce em multifacetadas instâncias e planos. É constitutivo e constituinte da realidade, formando um todo orgânico em defesa de múltiplos interesses. 
processo de democratização, é mediação política operativa de exercício e agregação desses novos valores. O espaço político é o espaço de consenso e conflito, que não deve ser negado, mas reconhecido e enfrentado.

Contudo, as diferenças e as divergências entre os diversos sujeitos não pode inviabilizar a concretização da finalidade das ações dos Conselhos. A luta pela efetivação dos princípios e diretrizes vinculados àquela política pública, à proteção dos direitos dos vários grupos sociais, não pode ser questionada, isto é unidade na diversidade (COUTINHO, 2000).

As diferenças aceitas como negociáveis ${ }^{11}$ são aquelas que não desvinculam a finalidade daquele fórum, uma vez que, a desvinculação à finalidade termina por destituir o próprio fórum; por isso, entende-se ser uma das tarefas iniciais ${ }^{12}$ às práticas conselhistas, a exposição e a discussão clara e objetiva das definições, competências e responsabilidades daquele fórum e do papel dos atores sociais ali representados, para que possa encaminhar o alcance da finalidade.

Outro aspecto relevante, é que as discussões que envolvem decisão e opinião, a partir do que o sujeito considera melhor, mais adequado, que pode estar argumentativamente embasada em uma lógica de manutenção ou de contraposição da ideologia dominante. Qualquer que seja a opinião - consciente ou alienada - deve ser incentivado sua exposição, debate. Deve-se chegar ao consenso por meio das múltiplas e variadas discussões, tantas quantas permitam a cada sujeito político, diante dos objetivos colocados aquele espaço, ter esclarecido suas dúvidas. Isso significa, na maioria das situações, aceitar a divergência e, portanto, o conflito. Em processos de maior reflexão e com grupos mais articulados e conscientes politicamente, os debates são mais acirrados, em outras, nem tanto ou são inexistentes, mas em qualquer modalidade é exigida o pluralismo.

\footnotetext{
${ }^{11}$ Para melhor entendimento do que seja negociação, apropria-se de uma definição de DEMO (1988): "Negociação significa o tratamento de divergências sobre o pressuposto das oportunidades equalizadas. Ou seja, de igual para igual, pelo menos em tese. Nem se imagina que a negociação acabe com as divergências. $\mathrm{O}$ que se pretende é a acomodação dela em patamares que permitam a convivência e a realização relativa dos interesses específicos." (p. 77).

${ }^{12}$ Os Conselhos, têm trocas freqüentes dos atores representantes. Além de todas as outras considerações já feitas neste texto sobre representação, entende-se que, durante um bom tempo ainda, "essas tarefas primeiras, iniciais" deverão ter caráter permanente.
} 


\subsection{PLURALISMO DOS SUJEITOS COLETIVOS: RECONHECIMENTO DA} AUTONOMIA E DA DIFERENÇA ENTRE OS SUJEITOS POLÍTICOS COLETIVOS

O pluralismo assumido nessa síntese,

[...] não é sinônimo de ecletismo. É sinônimo de abertura para o diferente, de respeito pela posição alheia, considerando que essa posição, ao nos advertir para os nossos erros e limites, e ao fornecer sugestões, é necessária ao próprio desenvolvimento da nossa posição e, de modo geral da ciência. [...] Não é apenas tolerância de quem tem a verdade no bolso e tolera a existência do diferente. Não. É uma posição de abertura de quem julga fundamental a tolerância para o progresso da ciência, para o enriquecimento da própria posição (COUTINHO, 1995, p. 14).

Nesse sentido, o pluralismo refere-se à prática assumida pelos sujeitos políticos coletivos, com uma vontade coletiva ${ }^{13}$ que os una. Com isso, já se delimitam duas deferências: uma de que as discussões e seus embates, nos espaços políticos aqui considerados, não podem ser individuais, orientado pelo que cada sujeito acha ou pensa, mas deve refletir o interesse daquele coletivo que o sujeito representa.

O coletivo representado não é estabelecido pela soma e/ou subtração das diferentes opiniões, dos diferentes sujeitos que compõem aquele segmento social, grupo de entidades, ou órgão governamental, mas representa de direito (mesmo que de fato não o faça) o projeto político daquele coletivo representado. No entanto, e aqui a segunda deferência, o projeto político não pode vincular-se a interesses corporativos, fragmentados, particularistas, que percebem apenas as necessidades e demandas daquele grupo social, grupo de entidades, etc.,

\footnotetext{
13 “Essa vontade aponta no sentido da formação de um 'bloco histórico’[...], onde múltiplos interesses são articulados.[...]." (COUTINHO, 1995, p. 10). Mas elas têm uma finalidade em comum.
} 
mas deve vincular-se a um projeto coletivo. Os Conselhos de Políticas Públicas e de Defesa de Direitos, devem se vincular a luta, preservação e avanços dos direitos de cidadania e da qualidade dos serviços prestados. Essa é a diretriz que deve veicular a vontade coletiva daqueles sujeitos que desejam a constituição de uma outra forma de viver em sociedade. Quer-se " [...] construir uma consciência ética universal, fundada na unidade de alguns valores humanistas básicos e na diversidade dos modos de explicitá-los" (COUTINHO, 1995, p. 16).

Assim, pluralismo diz respeito ao reconhecimento da autonomia e da diferença entre os sujeitos políticos coletivos, não negando, antes pelo contrário, buscando "uma unidade política, a formação de uma vontade geral ou coletiva, hegemônica, a ser construída pela via da negociação e do consenso" (COUTINHO, 2000, p. 37).

\section{CONSIDERAÇÕES FINAIS}

Os Conselhos aqui veiculados, espaços de complementaridade e de visibilidade, configuram-se como instâncias de intermediação, negociação, conflito e consenso e, assim, precisam ser percebidos como unidades repletas de contradições. Em vista disso, podem ser (e com certeza, em um número significativo de casos o são) espaços de manutenção e legitimação servil e, portanto, de regulação das propostas hegemônicas, destarte, de não controle social. A ação mobilizadora em formas de resistência e de alternativas contrahegemônicas, ao mesmo tempo em que é processo a ser construído, torna-se elemento indispensável ao aumento da capacidade reflexiva e organizativa da população.

Destarte, qualquer reflexão acerca de processos que envolvam democratização da esfera pública e participação social não pode negligenciar a compreensão acerca da realidade social, política e econômica atual e, nessa, seus limitantes e suas possibilidades, bem como as múltiplas relações sociais estabelecidas, nesse cenário, entre os diferentes atores sociais. De forma sintética, pode-se afirmar que a 
[...] globalização hegemônica tem devorado, não só as promessas do progresso, da liberdade, da igualdade, da não descriminação e da racionalidade, como a própria idéia da luta por elas. Ou seja, a regulação social hegemônica deixou de ser feita em nome de um projeto de futuro e com isso deslegitimou todos os projetos de futuros alternativos antes designados como projetos de emancipação social. A desordem automática dos mercados financeiros é a metáfora de uma forma de regulação social que não precisa da idéia de emancipação social para se sustentar e legitimar. Mas paradoxalmente, é dentro deste vazio de regulação e de emancipação que estão surgindo em todo mundo iniciativas, movimentos, organizações que lutam simultaneamente contra as formas de regulação que não regulam e contra as formas de emancipação que não emancipam (SANTOS, 2002, p. 17).

$\mathrm{Na}$ direção do fortalecimento dessas novas iniciativas, Santos (2014) defende a perspectiva da construção de uma nova teoria democrática. $O$ autor acredita que há necessidade de construir-se uma nova direção, capaz de agregar uma luta política articulada entre os princípios do Estado e da comunidade sob a égide deste último (SANTOS, 2014). É uma reforma simultânea do Estado e da sociedade civil, que conjuga democracia representativa e democracia participativa, que possibilita a garantia da efetividade do potencial democratizante de cada um deles contra o que o autor chama de fascismos pluralistas (SANTOS, 2014).

Para que isso aconteça, é preciso que se tenha clareza de algumas questões: uma delas é a necessária refundação democrática da sociedade civil, que passa pela transformação de suas práticas, uma vez que as mesmas têm demonstrado, em muitas situações, reproduzir os mesmos vícios que perpassam algumas das ações do Estado: promiscuidade, autoritarismo, benesse, corporativismo, entre outros. 
Os Conselhos, como unidades potencialmente constituidoras da garantia de direitos tornam-se espaços políticos propícios à veiculação de ações contrahegemônicas. Ações evidenciadas por conflitos, o que, " [...] em nossos espaços institucionais, não chegam a pôr em questão a dominação, mas que é o caminho pelo qual se pode engendrar (nunca necessariamente) a contra-hegemonia" (PALMA, 1986, p. 97).

A crença na possibilidade de ações contra-hegemônicas baseia-se na história da organização social das classes subalternas. As conquistas por democracia, direitos civis, políticos e econômicos, entre outras, foram resultado da luta, do embate e da organização dessas classes contra as diretrizes e práticas do liberalismo. Não foram, assim, dádivas, nem fizeram parte da compreensão da elite dominante de que isso era imprescindível para melhor qualidade de vida das classes subalternas. Logo, "[...] seria um equívoco histórico, mas também uma injustiça contra os trabalhadores atribuir à burguesia algo que foi conquistado contra ela" (COUTINHO, 2000, p. 61). A construção da emancipação humana passa pela organização política das classes subalternas contra a lógica hegemônica de mercado.

A análise aqui realizada parte, também, do pressuposto de que ainda não se tem, no Brasil, uma esfera pública constituída nos padrões pensados por aqueles que almejam um projeto societário calcado na defesa da emancipação humana. Raichelis (1998) é de posição, com a qual concorda-se, que a esfera pública desejada e a ser construída é expressa

[...] fundamentalmente pela inscrição dos interesses das maiorias nos processos de decisão política. Inerente a tal movimento, encontra-se o desafio de construir espaços de interlocução entre sujeitos sociais que imprimam níveis crescentes de publicização no âmbito da sociedade política e da sociedade civil, no sentido da criação de uma nova ordem democrática valorizadora da universalização dos direitos de cidadania. (RAICHELIS, 1998 25-26). 
A visualização das possibilidades aqui expostas não nega os limitantes às mesmas, resumidamente indicados na Introdução. Esses devem ser claramente definidos, compreendidos e explicados, pois definem a realidade sob a qual quer-se construir as alternativas contra-hegemônicas. Não se negam, pois, as muitas dificuldades à sua concretização, entre as quais se destacam:

- a pequena tradição democrática no País e, na contramão, a grande tradição autoritária que dificulta a internalização, por parte da população em geral, de princípios e comportamentos democráticos;

- a perspectiva veiculada pela ideologia dominante, avalizada através de seu repasse avassalador e diário pelos meios de comunicação, de que a orientação política econômica dominante é a única alternativa possível;

- a não-incorporação da esfera pública enquanto espaço de interesses coletivos e não-individuais que reproduzem a cultura patrimonialista de tutela, de favor;

- a dificuldade de articulação das diferentes instâncias participativas, associada a baixa experiência para o trabalho em rede;

- o baixo nível de acesso a informações por grande parte da população, que não encontra subsídios para a reinvindicação de seus direitos e a participação consciente;

- a falta de organização política da população que a impede de perceber a "força" do coletivo;

- a forma de representação nos conselhos, onde, não raras vezes, o representante assume o papel de porta-voz de si mesmo.

Destarte, muitas são as críticas a atuação dos conselhos. Tatagiba (2002) em pesquisa sobre três dos principais conselhos em âmbito Nacional (Saúde, Assistência e Criança e Adolescente) identifica dificuldades e entraves a efetivação dos mesmos, tanto como espaços democráticos de decisão, quanto como espaço educacional na promoção da cidadania. Nesses arranjos institucionais inéditos a dinâmica de funcionamento nem sempre permite que esses espaços inovadores se traduzam em práticas políticas inovadoras no âmbito da gestão do espaço público.

Entre as razões apresentadas por Tatagiba (2002), destaca-se a questão da paridade, considerada condição preliminar para a disputa entre posições e 
interesses divergentes no interior dos Conselhos, que tem ficado reduzida a sua dimensão numérica. Isso resulta em não equilíbrio no processo decisório. Aliase a isso, a não qualificação, a contento, para as atribuições de conselheiro e o que essa requer. Como produto da cultura política autoritária, excludente, e patrimonialista há: a) dificuldade dos conselheiros lidarem com a pluralidade e as divergências políticas nela contida; b) vínculo frágil entre os representantes e a representação conferida, alta rotatividade e grande número de ausências; c) centralização da agenda temática ao governo o que confere um controle do Estado sobre o que será discutido. Decorre disso, em muitos casos, a mera legitimação das decisões do governo; d) não cumprimento da função deliberativa do Conselho, onde a participação assume contornos mais reativos do que propositivos (a não decisão também é estratégia política de muitos governantes); e) acomodações políticas, trocas eleitoreiras e corrupção que operam como orientação a destinação de verbas públicas. Isso alimenta e reproduz a lógica da participação alienada, da não-democratização da esfera pública.

Contudo, apesar das suas limitações e da distância entre o idealizado quando da proposição desses Conselhos e sua efetiva operacionalização, entende-se que este espaço é fértil ao desenvolvimento do controle social, da participação consciente e transformadora da realidade, da prática democrática e, portanto, da efetivação de aprendizagens fundamentais ao exercício do poder que a representatividade nesses espaços delega àqueles que usufruem da posição de conselheiros e a quem cabe também o papel de disseminador das informações a que tem acesso.

Trata-se, portanto, de unidades políticas, onde o poder da sociedade pode e deve expressar-se para intervir nas políticas públicas de modo a que estas preservem o bem comum.

Para que este espaço se efetive, a participação que o possibilita e dá forma, não pode ser de qualquer tipo. Precisa ser uma participação consciente, comprometida, representadora, de fato, dos interesses coletivos. Estar a serviço dos interesses coletivos significa evitar tornar-se (mesmo que inconscientemente) representante de si mesmo e desta forma, vulnerável a manipulação de interesses particularizados. 
Após vários anos de experiência com a efetivação dos Conselhos, mantém-se como desafios permitir que os setores tradicionalmente excluídos possam influenciar no processo de produção e operacionalização de políticas públicas, com competência (capacitação) e tornar esses espaços gradual e permanentemente, em espaços de aprendizagem para a participação, o exercício do poder e da democracia.

Por último cabe destacar que a participação garantidora da preservação do bem coletivo e de exercício democrático é a que caminha na direção da emancipação humana.

\section{REFERÊNCIAS BIBLIOGRÁFICAS}

BATTINI, Odária. Das referências teórico metodológicas. In: BATTINI, Odária (Org.). Assistência social: constitucionalização, representação, práticas. São Paulo: Veras, 1998. p. 21-57. (Série temas 2).

BOBBIO, Norberto. O conceito de sociedade civil. Rio de Janeiro: Graal, 1994.

BRAVO, Maria Inês Souza. Gestão democrática na saúde: o potencial dos conselhos. In: BRAVO, Maria Inês Souza; PEREIRA, Potyara A.P. (Orgs.). Política social e democracia. São Paulo: Cortez; Rio de Janeiro: UERJ, 2001. p. 43-66.

CAMPOS, Edval Bernardin; MACIEL, Carlos Alberto Batista. Conselhos paritários: o enigma da participação e da construção democrática. Revista Serviço Social e Sociedade, São Paulo: Cortez, n. 55, p. 143-155, 1997.

CARDOSO, Franci Gomes. Organização das classes subalternas: um desafio para o Serviço Social. São Paulo: Cortez; Maranhão: Ed. Da UFM, 1995.

CARVALHO, Maria do Carmo A.A.; TEIXEIRA, Ana Cláudia C. (Org.). Conselhos gestores de políticas públicas. Pólis. São Paulo: Publicações Pólis, 37, 2000. 
CHAUÍ, Marilena. Considerações sobre a democracia e os obstáculos à sua concretização. In: TEIXEIRA, Ana Cláudia Chaves. (Org.). Os sentidos da democracia e da participação. São Paulo: Instituto Pólis, 2005. p. 23-30.

CHAUÍ, Marilena. Brasil: Mito fundador e sociedade autoritária. São Paulo: Perseu Abramo, 2001.

COELHO, Vera Schattan P.. A democratização dos Conselhos de Saúde: o paradoxo de atrair não aliados. Novos Estudos - CEBRAP, n.78 São Paulo July 2007. Disponível em:

http://www.scielo.br/scielo.php?script=sci_arttext\&pid=S010133002007000200009. Acesso em: 12 nov 2015.

COLIN, Denise Ratmann Arruda. Representação política: conceitos, configurações e paradoxos. In: BATTINI, Odária (Org.). Assistência social: constitucionalização, representação, práticas. São Paulo: Veras, 1998. p.133193. (Série temas 2).

COSTA, Vanda Maria Ribeiro. Teoria democrática e conselhos de políticas sociais. In: BRAVO, Maria Inês Souza; PEREIRA, Potyara A.P. (Orgs.). Política social e democracia. São Paulo: Cortez; Rio de Janeiro: UERJ, 2001. p. 87-112.

COUTINHO, Carlos Nelson. Contra a corrente: ensaios sobre democracia e socialismo. São Paulo: Cortez, 2000.

Pluralismo: dimensões teóricas e políticas. In: Cadernos ABESS. São Paulo: Cortez, n. 4, julho, p. 05-17, 1995.

Gramsci: um estudo sobre seu pensamento político. 2.ed. Rio de Janeiro: Campus, 1992. 
. Representação de interesses, formulação de políticas e hegemonia. In: TEIXEIRA, Sonia Fleury (Org.). Reforma sanitária: em busca de uma teoria. São Paulo: Cortez; Rio de Janeiro: Abrasco, 1989. p.119-138.

DEGENNSZAJH, Rachel Raichelis. Desafios da gestão democrática das políticas sociais. In: Capacitação em serviço social e política social, Brasília: UnB, Centro de Educação Aberta, Continuada a Distância, módulo 3, 2000. p. 58-69.

DAGNINO, Evelina. Construção democrática, neoliberalismo e participação: os dilemas da confluência perversa. Política \& Sociedade, n. 5, p. 139-164, out. 2004.

DEMO, Pedro. Participação é conquista. São Paulo: Cortez: Autores Associados, 1988.

DURÁN, Paulo Renato Flores; GERSCHMA, Silvia. Desafios da participação social nos conselhos de saúde. Saúde e sociedade. Vol. 23, n. 3. São Paulo, jul/set $2014 . \quad$ Disponível em: http://www.scielo.br/scielo.php?script=sci_arttext\&pid=S010412902014000300884. Acesso em: 4 abr 2016.

FOUCAULT, Michel. Microfísica do poder. Tradução de Roberto Machado. Rio de Janeiro: Graal, 1986.

GOHN, Maria da Glória. O protagonismo da sociedade civil: movimentos sociais, ONGs e redes solidárias. São Paulo: Cortez, 2005.

. Conselhos Gestores e Participação Sociopolítica. 4ª ed. São Paulo: Cortez, 2011.

GRAMSCI, Antônio em seus textos: Cartas do cárcere. 3. ed. Rio de Janeiro: Civilização Brasileira, 1987. 
. Os intelectuais e a organização da cultura. 5. ed. Rio de Janeiro: Civilização Brasileira,1985.

MOTA, Ana Elizabete. Questão social e Serviço Social: um debate necessário. IN: MOTA, Ana Elizabete. (org.). O mito da assistência social: ensaios sobre Estado, política e sociedade. 4 ed. São Paulo: Cortez, 2010. pp. 21-57.

NOGUEIRA, Marco Aurélio. Um Estado para a sociedade civil: temas e políticos da gestão democrática. $2^{\mathrm{a}}$ ed.. São Paulo: Cortez, 2005.

OLIVEIRA, Mara de. Reformas Estruturais de Segunda Geração e Cúpula das Américas: a mudança de estratégia política de dominação econômica na América Latina. 2005. 365f. Tese (Doutorado em Serviço Social) - Programa de Pós-Graduação em Serviço Social, Pontifícia Universidade Católica do Rio Grande do Sul (PUCRS), Porto Alegre, 2005.

PALMA, Diego. A prática dos profissionais: o caso do serviço social. São Paulo: Cortez; Lima (Peru): CELATS, 1986

PEREIRA, Potyara A.P. Estado, regulação social e controle democrático. In: BRAVO, Maria Inês Souza; PEREIRA, Potyara A.P. (Org.). Política social e democracia. São Paulo: Cortez; Rio de Janeiro: UERJ, 2001, p. 25-42.

. Necessidades humanas: subsídios à crítica dos mínimos sociais. São Paulo: Cortez, 2000.

PNAS - Política Nacional de Assistência Social. In: Ministério do Desenvolvimento Social e Combate à Fome. Sistema Único de Assistência Social. Brasília, nov. 2004.

PRATES, Jane Cruz. Discussões sobre práticas conselhistas, 2003. 
RAICHELIS, Rachel. Esfera pública e conselhos de assistência social: caminhos da construção democrática. São Paulo: Cortez, 1998, p. 25-84 e p. 199-250.

SÁ, Maria José Comparini Nogueira de; PORTO, Maria Teresa Dalla Fontana Pinto Moreira. Controle Público e o SUS. In: ILBANEZ, Nelson; ELIAS, Paulo Eduardo Mangeon; SEIXAS, Paulo Henrique D’Angelo (orgs). Políticas e Gestão Pública em Saúde. São Paulo: Hucitec Editora, 2011.

SADER, Emir. Para outras democracias. In: SANTOS, Boaventura de Souza (Org.). Democratizar a democracia: os caminhos da democracia participativa. Rio de Janeiro: Civilização Brasileira, 2002. p. 651-679.

SANTOS, Boaventura de Souza (Org.). Democratizar a democracia: os caminhos da democracia participativa. Rio de Janeiro: Civilização Brasileira, 2002.

A cor do tempo quando foge: uma história do presente. Crônicas 18862013. São Paulo: Cortez, 2014

TATAGIBA, Luciana. Os Conselhos Gestores e a Democratização das Políticas Públicas no Brasil. In: DAGNINO, Evelina (org). Sociedade Civil e espaços públicos. São Paulo: Paz e Terra, 2002.

VÁSQUEZ, Adolfo Sanches. Filosofia da práxis. Tradução de Luiz Fernando Cardoso. Rio de Janeiro: Paz e Terra, 1990. p. 245-311. 